\title{
Kanttekeningen bij het Raamplan 2001 artsopleiding
}

\author{
H.M.J. Raghoebar-Krieger, W. Bender, D.Th. Sleijfer
}

\begin{abstract}
Samenvatting
Inleiding: De eindtermen voor de basisartsopleiding zijn vastgelegd in het raamplan. Echter, de Begeleidingscommissie raamplan is van mening dat dit document niet wordt gebruikt zoals bedoeld. Vanwege het toenemende belang van eindtermen voor zowel de basisartsopleiding als de vervolgopleiding is het relevant te weten welke invloeden een rol spelen bij het gebruik van het raamplan. Daarom wordt nagegaan of er knelpunten zijn in de wijze waarop de begeleidingscommissie zorg heeft besteed aan het bepalen en omschrijven van de eindtermen in het raamplan.
\end{abstract}

Beschrijving: Vanuit het gezichtspunt van vier onderwijskundige thema's wordt vastgesteld hoe de eindtermen zijn bepaald en omschreven.

Deze thema's zijn: inventarisatie, evaluatie, formulering en classificatie. Het inventarisatieproces van de eindtermen wordt breed gedragen en is geactualiseerd. De eindtermen zijn alle geformuleerd in handelingen die veranderingen beogen in het gedragsrepertoire van de student, maar er is variatie in de abstractiegraad. De classificatie van eindtermen vertoont een logische structuur in kennis, vaardigheden en gedrag. Knelpunten zijn gevonden in: (1) de algemene formuleringen, waardoor sommige eindtermen niet direct praktisch toepasbaar zijn; (2) inconsistenties in de classificatie van kennis, vaardigheden en gedrag tussen verschillende onderdelen van het raamplan; (3) het ontbreken van de functie van de 'problemen'.

Beschouwing en conclusie: Het raamplan is met zorg samengesteld, maar om beter gebruik te bevorderen, is het nuttig de algemeen geformuleerde eindtermen uit te werken naar een concreet niveau waarop leeruitkomsten meetbaar zijn, de inconsistenties te verhelderen en de functie van de problemensectie te heroverwegen. (Raghoebar-Krieger HMJ, Bender W, Sleijfer DTh. Kanttekeningen bij het Raamplan 2001 artsopleiding. Tijdschrift voor Medisch Onderwijs 2006;25(2):75-82.)

\section{Inleiding}

Een belangrijke ontwikkeling in het medisch onderwijs van de afgelopen decennia is de totstandkoming van gemeenschappelijke eindtermen voor de opleiding tot basisarts, vastgelegd in het Raamplan 1994 artsopleiding ${ }^{1}$ en bijgesteld in het Raamplan 2001 artsopleiding. ${ }^{2}$ De behoefte aan eindtermen was groot, omdat verbeteringen in het medisch onderwijs noodzakelijk waren. ${ }^{3-4}$ Bewindslieden van het Ministerie van Onderwijs en Wetenschappen en het Ministerie van Volksgezondheid, Welzijn en Sport verzochten daarom het disciplineoverlegorgaan Medische Wetenschappen van de Vereniging van Samenwerkende Nederlandse Universiteiten in 1991 de eindtermen voor de artsopleiding op te stellen. Het vaststellen c.q. herzien van de eindtermen werd begeleid door een begeleidingscommissie met vertegenwoordigers uit verschillende organen. ${ }^{2}$

In het Raamplan wordt een overzicht gegeven van de eindtermen waaraan elke arts aan het einde van zijn opleiding moet voldoen. ${ }^{1-2}$ Sinds de verschijning van 
het raamplan hebben veel faculteiten dit document gebruikt als uitgangspunt voor discussies over de inhoud, vormgeving en organisatie van het onderwijs, en ook als basis voor onderzoek van onderwijs. ${ }^{5-9}$ Het raamplan heeft zowel in binnen- als buitenland veel aanzien gekregen en er is veel buitenlandse belangstelling voor de vertaling. ${ }^{2} 10$ Echter, de begeleidingscommissie was van mening dat de faculteiten het Raamplan 1994 artsopleiding niet altijd gebruiken zoals bedoeld. ${ }^{2}$ Zij concludeert dat vooral de disciplinegebonden eindtermen (ziektebeelden en vaardigheden), die in de bijlage zijn opgenomen, voor allerlei oneigenlijke activiteiten werden gebruikt, bijvoorbeeld door opname in log-/ stageboeken. De begeleidingscommissie stelde vast dat de lijsten gebruikt worden als afvinklijsten, waardoor de aandacht van studenten zou worden afgeleid van waar het werkelijk om gaat: het leren oplossen van problemen. Daarnaast was de begeleidingscommissie bezorgd dat de ziektebeelden- en vaardighedenlijsten door disciplines misbruikt konden worden voor het claimen van onderwijstijd. Een laatste bezwaar was dat dergelijke lijsten de suggestie zouden wekken volledig te zijn. De begeleidingscommissie stelde dat volledigheid per definitie onmogelijk was en dat de lijsten ook niet met die pretentie waren opgesteld. Om deze redenen wilde de begeleidingscommissie de disciplinegebonden eindtermen in de herziene versie van het raamplan dan ook niet meer opnemen.

Het Landelijk Overleg Co-Assistenten (LOCA) en de wetenschappelijke verenigingen hechtten echter veel waarde aan de disciplinegebonden eindtermen. ${ }^{2}$ Veel studenten vonden de handleiding handig en onmisbaar als hulpmiddel bij de studie. Het LOCA was bovendien van mening dat de angst om de lijsten als streep-/bingokaart te gebruiken ongegrond was. Het LOCA vreesde dat met het laten vallen van de disciplinegebonden eindtermen de huidige kwaliteitsnorm die gesteld wordt aan kennis en vaardigheden verlaagd zou worden, doordat alleen de vagere algemene eindtermen overbleven. Daarom verzocht het LOCA om de disciplinegebonden eindtermen, bij voorkeur ongewijzigd, te handhaven in het herziene raamplan. De begeleidingscommissie gaf daarom de opdracht aan een projectgroep om een agendanotitie te schrijven, waarin duidelijk moest worden welke functie eindtermen vervullen en voor wie ze belangrijk zijn. ${ }^{2}$ Op grond van de analyse van de projectgroep werden de disciplinegebonden eindtermen in het Raamplan 2001 artsopleiding in een separate bijlage opgenomen. Hiermee behoorden ze uitdrukkelijk niet tot de opleidingseisen.

De bijstelling van de eindtermen in het Raamplan 1994 artsopleiding heeft reeds plaatsgevonden. Het Raamplan 1994 artsopleiding en het Raamplan 2001 artsopleiding hebben volgens de begeleidingscommissie dezelfde uitgangspunten. ${ }^{2}$ Daardoor blijft de kans groot dat de faculteiten het herziene raamplan niet gebruiken zoals de begeleidingscommissie dat bedoelt. Vanwege het toenemende belang van eindtermen in zowel de basisartsopleiding als in de vervolgopleiding is het relevant te weten welke invloeden een rol spelen bij het gebruik van het raamplan. Een logische stap is om eerst na te gaan of er knelpunten zijn in de wijze waarop de begeleidingscommissie zorg heeft besteed aan het bepalen en omschrijven van de eindtermen uit het raamplan. Dit wordt gedaan door het Raamplan 2001 artsopleiding vanuit het gezichtspunt van de onderwijskunde te bekijken, meer in het bijzonder vanuit de desiderata die De Corte et al. voor eindtermen hebben geformuleerd. Zij bepleiten dat aan vier thema's bijzondere aandacht wordt geschonken: inventarisatie, evaluatie, formulering en classificatie. ${ }^{14-15}$ 


\section{Het bepalen en omschrijven van de eindtermen uit het Raamplan}

\section{Inventarisatie: verzamelen en funderen van eindtermen}

Bij het verzamelen en funderen van eindtermen wordt bepaald welke veranderingen het onderwijs in het gedragsrepertoire van de student wil verwezenlijken. Hierbij is het van belang dat er een verantwoorde keuze wordt gemaakt. ${ }^{14-15}$ In het Raamplan 2001 artsopleiding is hieraan uitgebreid aandacht besteed door de veranderingen die men in het gedrag nastreeft, te beschrijven in drie hoofdstukken. In de eerste plaats zijn de zes belangrijkste eigenschappen van de arts omschreven in het 'profiel' van de arts. Vervolgens worden in de algemene eindtermen die kennisinhouden, vaardigheden en gedrag beschreven, die nodig zijn om te kunnen functioneren als een goed arts. Dit functioneren is toegespitst op vier thema's: medische aspecten, wetenschappelijke aspecten, persoonlijke aspecten en aspecten in relatie tot de maatschappij en het gezondheidszorgsysteem. Tenslotte worden in de probleemlijst 'problemen' genoemd die iedere arts moet kunnen aanpakken. Hiermee wordt het belang van het proces van klinisch denken en handelen benadrukt. De algemene eindtermen en de problemen vormen het 'corpus': deze onderdelen moeten beschouwd worden als de opleidingseisen. ${ }^{2}$ Deze onderdelen zijn vastgelegd in een Algemene Maatregel van Bestuur bij de Wet op de Beroepen in de Individuele Gezondheidszorg (BIG) en hebben daarmee een wettelijke status. ${ }^{16}$ Niet tot de eindtermen behorend, maar zuiver als illustratie bedoeld (en daarom ook in een bijlage opgenomen), is de disciplinegebonden lijst van vaardigheden en ziektebeelden. Deze lijst vormt het 'werkgeheugen' waarmee de algemene eindtermen en de problemen op een bepaald niveau aangepakt dienen te worden. ${ }^{2}$ De keuzes voor deze inhoud van het raamplan worden breed gedragen, dat wil zeggen: veel personen zijn bij de totstandkoming betrokken geweest. ${ }^{1-2}$

\section{Evaluatie: het vaststellen of de eind- termen nog juist zijn}

Het tweede thema dat van belang is, betreft het vaststellen of de nagestreefde eindtermen nog juist en actueel zijn. Een regelmatige herziening van de eindtermen is nodig, omdat de maatschappij zich snel ontwikkelt. Het Raamplan 1994 artsopleiding stelt dat ook. De begeleidingscommissie is van mening dat de uitgangspunten van het Raamplan 1994 artsopleiding en het Raamplan 2001 artsopleiding identiek zijn, maar op een aantal punten zijn er wel wijzigingen. ${ }^{2}$ Naast een redactionele bijstelling betreffen de veranderingen vooral de systematiek en formulering van de algemene eindtermen. De probleemlijst heeft nu een duidelijker indeling: de problemen worden nu orgaansgewijs geordend. Daarnaast is de vaardighedenlijst disciplineonafhankelijk gemaakt en zijn niveau-aanduidingen verdwenen. De ziektebeeldenlijst is ongewijzigd. Door zowel de vaardigheden als de ziektebeelden in een bijlage op te nemen, wordt de illustratieve functie van deze lijsten echter meer dan voorheen benadrukt.

\section{Formulering van eindtermen}

Eindtermen kunnen geformuleerd worden in verschillende maten van abstractie (algemene versus concrete eindtermen). Hoe concreter het doel, des te gemakkelijker het te vertalen is in opdrachten en des te groter de kans op een systematische manier van werken. ${ }^{13-15}$

De eindtermen uit het raamplan worden omschreven in handelingen of gedragingen die veranderingen beogen in het gedragsrepertoire van de student, maar 
er is variatie in de abstractiegraad. In het raamplan wordt door de projectgroep een driedeling gehanteerd van abstract naar concreet niveau door:

1. een algemene beschrijving van de te bereiken leereffecten in een 'concept' (profiel van de arts);

2. een eerste specificatie van dit concept in een 'lijst van desidarata' (algemene eindtermen);

3. een tweede specificatie in een 'didactische en evaluatieve operationalisatie', respectievelijk: hoe bereik je eindtermen en hoe constateer je dat eindtermen bereikt zijn (ziektebeeldenlijst) (zie Aanhangsel 3, Raamplan 2001 artsopleiding). ${ }^{2} 17$

Deze driedeling maakt de functie c.q. status van de eindtermen goed zichtbaar. Echter, doordat de problemen niet worden ingedeeld, is de functie en status hiervan onduidelijk.

\section{Classificatie van eindtermen}

Het vierde thema heeft te maken met het ordenen van doelen in categorieën, zodat er een overzicht ontstaat van de inhouden van kennis, vaardigheden en gedrag. ${ }^{14-15}$ 18 In het raamplan zijn de eindtermen op overzichtelijke wijze geordend. In het profiel van de arts worden kennis, vaardigheden en gedrag niet separaat genoemd, maar zijn ze verenigd in zes belangrijke eigenschappen die de basisarts moet bezitten (bijvoorbeeld: 'de arts is wetenschappelijk gevormd'). In de algemene eindtermen worden kennis, vaardigheden en professioneel gedrag wel onderscheiden. In de probleemlijst worden deze items niet expliciet onderscheiden, maar de formulering dat een basisarts 'moet kunnen omgaan met' genoemde problemen, refereert uiteraard aan kennis, vaardigheden en gedrag. Dit geldt ook voor de ziektebeelden en vaardigheden. Door de niveau-aanduidingen (het ziektebeeld 'weten te plaatsen' en 'in de praktijk mee kunnen omgaan'; vaardigheid 'lege artis uit te voeren') kan ook worden afgeleid dat het hier om kennis, vaardigheden en gedrag gaat.

In het profiel van de arts, de algemene eindtermen, de probleemlijst en de ziektebeelden- en vaardighedenlijst is wel sprake van classificatie, maar deze classificatie is inconsistent met datgene wat er in Aanhangsel 3 van het raamplan zelf staat. ${ }^{2}$ In Aanhangsel 3 wordt geconcludeerd dat de ziektebeelden kennisdoelen zijn en daarom niet tot de opleidingseisen horen; de algemene eindtermen en de problemen horen wel tot de opleidingseisen. ${ }^{2}$ Hiermee wordt impliciet aangegeven dat het bij deze onderdelen om vaardigheden en gedrag gaat. Echter, in de algemene eindtermen (Hoofdstuk 5) wordt letterlijk aangegeven dat deze eindtermen ook betrekking hebben op kennis en dus kennisdoelen zijn (bijvoorbeeld: 'de arts beschikt over kennis met betrekking tot de normale levensfasen en de mogelijke verstorende factoren daarin'). ${ }^{2}$ Ook in Hoofdstuk 3 (p. 20) wordt vermeld dat de algemene eindtermen betrekking hebben op kennis. ${ }^{2}$ Voorts wordt in de probleemlijst niet expliciet over kennis, vaardigheden en gedrag gesproken. Er worden problemen genoemd die iedere arts moet kunnen aanpakken. De betekenis van 'aanpakken' is niet eenduidig, maar er kan worden verondersteld dat voor het aanpakken van een probleem zowel kennis, vaardigheden als gedrag nodig is. Tenslotte is de conclusie in Aanhangsel 3 dat kennis slechts van toepassing is op de ziektebeelden in tegenstelling tot datgene wat in de ziektebeeldenlijst zelf staat, namelijk: een arts moet een ziektebeeld weten te plaatsen (theorie) of daar in de praktijk mee om weten te gaan. ${ }^{2}$

\section{Beschouwing}

Om de vraag te kunnen beantwoorden welke invloeden een rol spelen bij het 
gebruik van het raamplan, heeft de analyse van de wijze waarop het raamplan zorg heeft besteed aan het proces van het bepalen en omschrijven van eindtermen nuttige informatie opgeleverd. Het raamplan is met zorg samengesteld en er is veel aandacht besteed aan de thema's die van belang worden geacht bij het vaststellen van eindtermen. Het verzamelen en funderen van de eindtermen wordt breed gedragen en is geactualiseerd. De eindtermen worden alle geformuleerd in handelingen die veranderingen beogen in het gedragsrepertoire van de student, maar er is variatie in de abstractiegraad. Het classificeren van de eindtermen vertoont een logische structuur in kennis, vaardigheden en gedrag. Echter, bij de analyse is een aantal knelpunten naar voren gekomen die wellicht leiden tot onduidelijkheid bij het gebruik van het raamplan.

In de eerste plaats speelt de variatie in de abstractiegraad van de eindtermen een mogelijke rol bij het gebruik van het raamplan. Het profiel van de arts heeft de hoogste mate van abstractie, gevolgd door de algemene eindtermen, de problemen, de vaardigheden en de ziektebeelden. Het profiel van de arts en de daaruit afgeleide algemene eindtermen zijn (vrij) algemeen geformuleerd en daardoor veelzijdig interpreteerbaar. Zij geven meer een kader aan om het curriculum af te bakenen. De problemen, vaardigheden en ziektebeelden zijn concreter, omdat deze specifiek aangeven om welk probleem, vaardigheid of ziektebeeld het zou moeten gaan in een leersituatie. Daarnaast wordt bij de ziektebeelden expliciet aangegeven op welk niveau (theorie-praktijk) met het ziektebeeld moet worden omgegaan. Aangezien concretere eindtermen een meer eenduidige basis bieden voor het ontwerpen van een onderwijsleersituatie dan abstracte eindtermen, ${ }^{13-14}$ is het dus niet zo verwonderlijk dat de ziektebeelden vaker zijn gebruikt bij de inrichting van het onderwijs dan de algemene eindtermen. Het operationaliseren van de algemene eindtermen naar een concreter niveau is tot nu toe onvoldoende gebeurd, ${ }^{9}$ terwijl het uitdrukkelijk wel de bedoeling was van de begeleidingscommissie. ${ }^{2}$ Het is daarom wenselijk dat de faculteiten hier meer aandacht aan besteden.

Bij het operationaliseren van de algemene eindtermen naar een concreter niveau is het belangrijk te formuleren wat de student die een bepaalde eindterm heeft bereikt er mee kan doen. Met andere woorden: de leeruitkomsten moeten gespecificeerd worden door een beschrijving te geven van hetgeen de student er mee moet kunnen demonstreren. Enkele woorden en uitdrukkingen die gebruikt kunnen worden in de formuleringen van doelstellingen zijn: beschrijven, opnoemen, aanduiden, herkennen, ordenen, construeren, het verschil of de gelijkenis aanduiden. ${ }^{14}$ Woorden die wegens hun gebrek aan eenduidigheid minder geschikt zijn, zijn: weten, begrijpen, inzicht hebben in, waarderen, beheersen. ${ }^{14}$ In het algemeen kan worden gesteld dat concrete leerdoelen tijdens en algemene leerdoelen aan het einde van de leerroute moeten worden bereikt. Voor het operationaliseren zijn verschillende methoden en technieken te gebruiken. ${ }^{13-14}$ Operationalisatie van de algemene eindterm 'in staat zijn om lichamelijk onderzoek uit te voeren' kan bijvoorbeeld plaatsvinden door onderscheid te maken in de volgende concrete aspecten:

1. Het type patiënt (bijvoorbeeld: 'cardiologische patiënt”. Ter illustratie kan hiervoor de probleemlijst of ziektebeeldenlijst gebruikt worden).

2. De aard van de vaardigheden die de student moet beheersen (bijvoorbeeld: 'auscultatie van het hart') en de daarbij behorende deelvaardigheden: 
- Klok en membraan van de stethoscoop kunnen gebruiken.

- Op vier plaatsen kunnen ausculteren.

- Kunnen noemen van afwijkingen in ritme of tonen.

- Souffles kunnen noemen en herkennen.

- Auscultatie uit kunnen voeren bij een patiënt in rug- en zijligging en in zittende positie.

In deze uitwerking zijn veel van de leereffecten in meetbaar gedrag te onderscheiden waarop de student beoordeeld kan worden. Eindtermen die in meetbaar gedrag worden onderscheiden zijn dan ook zeer waardevol. ${ }^{19}$

Een andere reden die een rol zou kunnen spelen bij het gebruik van het raamplan ligt in de onduidelijkheid van de functie van de eindtermen. De projectgroep die is ingesteld om de functie c.q. status van de eindtermen te bepalen, is naar onze mening onvolledig geweest in haar analyse. Voor alle eindtermen uit het raamplan wordt vastgesteld wat voor functie zij moeten hebben, behalve voor de problemen. Hierdoor is het niet duidelijk geworden hoe de faculteiten met de problemen om moeten gaan. Aangezien het indelingsschema dat in het raamplan wordt gehanteerd (zie Aanhangsel 3, Raamplan 2001 artsopleiding) goede handvaten biedt, ${ }^{2} 17$ is het aan te bevelen de problemen opnieuw in te delen en vervolgens hun functie vast te stellen.

Als de problemen opnieuw zijn ingedeeld volgens bovengenoemd indelingsschema, is het aannemelijk dat zij dezelfde functie krijgen als de ziektebeelden, namelijk: een middel om vast te stellen hoe de eindtermen bereikt kunnen worden en hoe vastgesteld kan worden dat ze bereikt zijn. Problemen zijn weliswaar van een abstracter niveau dan ziektebeelden, maar minder abstract dan concepten zoals het 'profiel van de arts' of een eerste specificatie van dit concept, zoals weergegeven in de algemene eindtermen. De problemen moeten net als de ziektebeelden gezien worden als middel om het diagnostisch en therapeutisch denken en handelen te oefenen. Een veelzijdig pakket aan problemen en ziektebeelden is daarbij belangrijk, omdat het beheersen van klinisch redeneren sterk afhankelijk blijkt te zijn van de specifieke inhoud van de aangeboden casus. Veel verschillende casuïstiek beïnvloedt het leren positief. ${ }^{20}$

Als ziektebeelden gebruikt mogen worden als middel om de algemene eindtermen te operationaliseren (zoals de projectgroep stelt), dan is de zorg die de begeleidingscommissie heeft ten aanzien van het gebruik van de ziektebeeldenlijst als afvinklijst ${ }^{2}$ niet reëel. De begeleidingscommissie is bezorgd dat de aandacht van studenten wordt afgeleid van waar het werkelijk om gaat, namelijk: het leren oplossen van problemen. Echter, deze zorg wordt niet uitgesproken ten aanzien van de problemen, terwijl problemen ook worden opgenomen in logboeken en worden gebruikt als afvinklijst, ${ }^{6}$ zonder dat gewaarborgd is dat een afgevinkt probleem het medische probleemoplossen heeft bevorderd. Terecht wijst Jolly erop dat met checklisten uit logboeken de leereffecten op de student niet kunnen worden beoordeeld, maar dat zij meer dienen als bron voor o.a. structuur en als informatie voor docenten voor een beoordelingsgesprek. ${ }^{21}$ Maar dat geldt dan voor zowel problemen als voor ziektebeelden.

Een laatste aspect dat een rol speelt bij het gebruik van het raamplan en een oorzaak zou kunnen zijn van onduidelijkheid, is de gevonden inconsistentie in de classificatie van kennis, vaardigheden en gedrag tussen Aanhangsel 3 en de overige hoofdstukken van het raamplan. Daarnaast is geconstateerd dat de gebruikte terminologie niet altijd expliciet genoeg is, zoals bijvoorbeeld het 'aanpakken' van 
problemen. In feite komt het erop neer dat als het raamplan zelf niet duidelijk genoeg is over de functie van bepaalde eindtermen, dit het juiste gebruik niet zal bevorderen.

\section{Conclusie}

Het bepalen en omschrijven van de eindtermen uit het raamplan is met zorg gebeurd. Het raamplan wordt breed gedragen en is geactualiseerd. De eindtermen worden geformuleerd in handelingen of gedragingen die veranderingen beogen in het gedragsrepertoire van de student, maar er is variatie in de abstractiegraad. Daarnaast zijn de eindtermen op redelijk overzichtelijke wijze geordend in kennis, vaardigheden en gedrag. Echter, er zijn wel een aantal knelpunten geconstateerd die kunnen leiden tot onduidelijkheid bij het gebruik van het raamplan. De formulering van de eindtermen is niet altijd even expliciet. Daarnaast is de inconsistentie in de classificatie van kennis, vaardigheden, en gedrag in de verschillende onderdelen van het raamplan verwarrend. Tot slot worden de problemen (in tegenstelling tot de algemene eindtermen en ziektebeelden) niet ingedeeld naar abstractiegraad, waardoor de functie van de problemen niet helder is. Meer duidelijkheid van de kant van de begeleidingscommissie over bovengenoemde knelpunten zal een beter gebruik van het raamplan kunnen doen bevorderen.

\section{Literatuur}

1. Metz JCM, Pels-Rijcken-van Erp Taalman Kip EH, Brand-Valkenburg BWM van den. Raamplan 1994 artsopleiding: eindtermen van de artsopleiding. Nijmegen: Universitair Publikatiebureau; 1994.

2. Metz JCM, Verbeek-Weel AMM, Huisjes HJ. Raamplan 2001 artsopleiding: bijgestelde eindtermen van de artsopleiding. Nijmegen: Mediagroep; 2001.

3. Metz JCM, Bulte JA, Paridon EJM van. Basisarts: bevoegd en bekwaam: eindrapport. Beleidsgericht onderzoek co-assistentschappen. Zoetermeer: Ministerie van Onderwijs en Wetenschappen; 1990.
4. Borst-Eilers E, Querido A, Kock van Leeuwen JAC de. Voorstel tot het invoeren van een algemene klinische vormingsperiode in het medisch onderwijscontinuüm. Rijswijk: Ministerie van Welzijn, Volksgezondheid en Cultuur; 1989.

5. Raghoebar-Krieger HMJ. The objectives-based logbook: a tool for evaluation of medical education [dissertation]. Wageningen: Ponsen \& Loojen BV; 2001.

6. Dolmans D, Schmidt A, Beek J van der, Beintema M, Gerver WJ. Does a student log provide a means to better structure clinical education? Med Educ 1999;33(2):89-94.

7. Soethout MBM, Verweij AMJJ, Tilburg W van. Algemene eindtermen van het Raamplan 1994 in de artsopleiding van de Vrije Universiteit. In: Verweij AMJJ, Albersnagel EA, Ten Cate ThJ, Denekens J, Dikkers JH, et al., editors. Gezond Onderwijs - 7. Houten/Zaventem: Bohn Stafleu van Loghum; 1998. p. 279-81.

8. Snellen-Balendong HAM. Het Raamplan 1994 in relatie tot de doelstellingen van de co-assistentschappen. In: Cate ThJ ten, Dikkers JH, Houtkoop E, Pollemans MC, Pols J, Smal JA, editors. Gezond Onderwijs - 5. Houten/Diegem: Bohn Stafleu van Loghum; 1996. p. 373-9.

9. Pols J. De beroepsvoorbereiding van studenten geneeskunde; verkenningen op het gebied van chronisch zieken [dissertation]. Groningen: Rijksuniversiteit Groningen: 2002.

10. Metz JCM, Stoelinga GBA, Pels Rijcken-van Erp Taalman Kip EH, Brand-Valkenburg BWM van den. Raamplan 1994: training of doctors in the Netherlands. Objectives of undergraduate medical education in the Netherlands. Nijmegen: University Publication Office; 1994.

11. Deetman WJ. Eindtermen en deugdelijkheidseisen, kwaliteitsbewaking in het funderend onderwijs: In: Creemers BPM, Hoeben WThJG, Koops K, editors. De kwaliteit van het onderwijs. Groningen: Wolters-Noordhoff; 1983:9-15.

12. Groot $\mathrm{AD}$ de. Begrip van evalueren. 's Gravenhage: Vuga; 1986.

13. Bie D de. Doelen formuleren in het onderwijs. 's Gravenhage: De Som; 1989.

14. Corte E de, Geerligs CT, Lagerweij NAJ, Peters JJ, Vandenberghe R. Beknopte didaxologie. Groningen: Wolters-Noordhoff; 1981.

15. Lowyck J, Verloop N. Onderwijskunde. Een kennisbasis voor professionals. Leuven: Wolters; 1995.

16. Besluit Opleidingseisen arts'ex wet BIG. Staatsblad van het Koninkrijk der Nederlanden. 's-Gravenhage; 1979:379.

17. Groot $\mathrm{AD}$ de. Hoe stelt men eindtermen op? Universiteit en Hogeschool 1974;20(5):213-32.

18. Franssen HAM, Jager A, Rinkema-Kohlman VW. Denken over doelen: een literatuurstudie naar 
het inventariseren, formuleren en classificeren van onderwijsdoelstellingen als bijdrage aan de eindtermendiscussie. Utrecht: Rijksuniversiteit Utrecht; 1987.

19. Learning objectives for medical student education, guidelines for medical schools: report I of the Medical school objectives Project. Acad Med 1999;74(1):13-8.

20. Vleuten CPM van der. Toetsing van medische competentie. In: Metz JCM, Scherpbier AJJA, Vleuten CPM van der, editors. Medisch onderwijs in de praktijk. 's-Gravenhage: Van Gorcum; 1995. p. 152-64.

21. Jolly B. Clinical logbooks: recording clinical experiences may not be enough. Med Educ 1999;33(2):86-8.
De auteurs:

Mw. dr. H.M.J. Raghoebar-Krieger is als onderwijskundige verbonden aan het Onderwijsinstituut van het Universitair Medisch Centrum Groningen, Rijksuniversiteit Groningen.

Dr. W. Bender is psycholoog, De Gast 69, 9801 AC Zuidhorn.

Prof. dr. D.Th. Sleijfer is hoogleraar klinisch onderwijs en internist-oncoloog, afdeling Interne Geneeskunde, Universitair Medisch Centrum Groningen, Rijksuniversiteit Groningen.

Correspondentieadres:

Mw. dr. H.M.J. Raghoebar-Krieger, Onderwijsinstituut, Universitair Medisch Centrum Groningen, Rijksuniversiteit Groningen, A. Deusinglaan 1, 9713 AV Groningen, tel.: 050-3633105, fax: 050-3633865, h.m.j.raghoebarkrieger@med.umcg.nl.

\section{Summary}

Introduction: The objectives of undergraduate medical education were laid down in Blueprint 2001, training of doctors in the Netherlands. However, the Central Coordination Committee of the Blueprint takes the view that the Blueprint is currently not being used as intended. The growing importance of objectives for both undergraduate medical education and postgraduate specialist training underlines the urgency of insight into factors that determine the Blueprint's use and misuse. That is why we explored bottlenecks in the procedure used by the Central Coordination Committee to develop the Blueprint's objectives.

Description: Using four generally accepted themes from educational literature (collection, evaluation, formulation and classification), we examined the development of the Blueprint's objectives. The objectives were collected to represent most disciplines and they have been revised since. All objectives are described as actions intended to alter students' behaviour and the descriptions vary in level of abstraction. The classification of the objectives follows a logical structure, i.e. knowledge, skills and attitude. Bottlenecks have been identified with regard to: (1) the general formulations, which made some objectives not feasible; (2) inconsistencies between different parts of the Blueprint with regard to the categories of knowledge, skills and attitude; (3) absence of a definition of the role of the Problems.

Conclusion: The Blueprint has been composed with great care. However, its implementation would be facilitated by: concrete definitions of the general objectives in such a way that outcomes can be measured; removing inconsistencies; re-evaluation of the function of the Problems section. (Raghoebar-Krieger HMJ, Bender W, Sleijfer DTh. Comments on Blueprint 2001, training of doctors in the Netherlands. Dutch Journal of Medical Education 2006;25(2):75-82.) 